\title{
CONSTRUCCIÓN DEL IMAGINARIO SOCIAL DE LAS TERAPIAS ALTERNATIVAS A TRAVÉS DEL DISCURSO EN REDES SOCIALES: CASO DE ESTUDIO DEL CANAL "TERAPIAS ALTERNATIVAS Y REMEDIOS NATURALES"1
}

\author{
Dra. Yolanda Cabrera García-Ochoa \\ Universidad de Valencia, Valencia, España \\ yolanda.cabrera@uv.es \\ ORCID iD: https://orcid.org/0000-0003-1584-3695 \\ Dra. Vanessa Roger Monzó \\ ESIC Business \& Marketing School, Valencia, España \\ vanessa.roger@esic.edu \\ ORCID iD: https://orcid.org/0000-0002-7498-0406
}

Recibido el 3 de diciembre de 2018

Aceptado el 11 de enero de 2019

\begin{abstract}
Resumen
El objetivo de esta investigación es analizar cómo se construye el imaginario social de las terapias naturales, complementarias y alternativas a través de su discurso en redes sociales. Para ello, se ha escogido el canal temático "Terapias alternativas y remedios naturales" de la plataforma YouTube. Se ha realizado un análisis de contenido de dicho canal y se han examinado las sinergias con la página de Facebook, y el sitio web que se vinculan al mismo, con la finalidad de determinar si, además de contribuir en la difusión de estas terapias, existe una intencionalidad distinta. El periodo de análisis del canal temático ha sido de un año: desde julio de 2017 a julio de 2018. Se ha seleccionado una muestra de 40 vídeos por año, ordenados en función del número de visualizaciones, y se han examinado las características comunes en cuanto a calidad, temáticas, posproducción y estilo de la narración. Los resultados evidencian que el canal se emplea como una plataforma de transmisión de contenidos con una postura favorable a este tipo de tratamientos. Del mismo modo, se constata el desarrollo de una estrategia de marketing orientada a una finalidad lucrativa.
\end{abstract}

Palabras clave: Terapias Alternativas, Redes Sociales, Imaginario Social, Marketing.

\footnotetext{
1 El presente trabajo ha sido desarrollado en el marco del proyecto de investigación "Estudio y clasificación de las terapias naturales, complementarias y alternativas a través de los medios de comunicación y de las redes sociales. Ideas y valores de transferencia al imaginario social" (CSO2014-57778-R), financiado por el Ministerio de Economía y Competitividad y por fondos FEDER de la Unión Europea.
} 


\title{
CONSTRUCTION OF THE SOCIAL IMAGINARY OF ALTERNATIVE THERAPIES THROUGH DISCOURSE IN SOCIAL NETWORKS: CASE STUDY OF THE CHANNEL "ALTERNATIVE THERAPIES AND NATURAL REMEDIES"
}

\begin{abstract}
The objective of this research is to analyze how the social imaginary of natural, complementary and alternative therapies is constructed through its discourse in social networks. For this, the thematic channel "Alternative therapies and natural remedies" of the YouTube platform has been chosen. An analysis of the content of this channel was carried out and synergies were examined with the Facebook page and the website linked to it, in order to determine whether, in addition to contributing to the diffusion of these therapies, there is a different intentionality. The analysis period of the channel has been one year: from July 2017 to July 2018 . A sample of 40 videos per year has been selected, ordered according to the number of visualizations, and their common characteristics have been examined in terms of quality, themes, postproduction and narrative style. The results show that the channel is used as a platform to transmit content with a favorable stance to this type of treatment. In the same way, the development of a marketing strategy oriented to a lucrative purpose is verified.
\end{abstract}

Keywords: Alternative Therapies, Social Networks, Social Imaginary, Marketing.

Cómo citar este artículo:

Cabrera, Y. y Roger-Monzó, V. (2019). "Construcción del imaginario social de las terapias alternativas a través del discurso en redes sociales: caso de estudio del canal "Terapias alternativas y remedios naturales", en Perspectivas de la Comunicación, Vol. 12, n 1. pp. 7999. 
Introducción

as denominadas Medicinas Complementarias y Alternativas (CAM por sus siglas en inglés) están formadas por diferentes técnicas y productos que, aunque en muchos casos se aplican para el tratamiento de enfermedades, en España, están fuera de los cauces de la medicina convencional (Cano-Orón, et al., 2018). Además, carecen de una regulación específica a diferencia de otros países europeos como Alemania, Bélgica o Francia, entre otros (Urios et al., 2006). Tanto el hecho de que no se integren en el sistema sanitario, como el debate generado en torno a la necesidad de regular o no estas prácticas, se debe a que no han sido sometidas a los rigurosos procesos de calidad y control de las agencias reguladoras de medicamentos (FDA en América y EMEA en Europa) y no existen evidencias científicas que avalen los resultados prometidos (Leaf et al., 2016). Sin embargo, estas circunstancias no impiden la proliferación de este tipo de terapias, así como el incremento de su mercado libre (Alonso et al., 2008).

Precisamente el mercado libre que existe con respecto a este tipo de remedios permite la propagación de mensajes como los analizados en este trabajo, presentes en canales temáticos de diferentes redes sociales en los que sujetos anónimos, sin contar con formación reglada, prescriben y recomiendan tratamientos, terapias y remedios alternativos, manifestando su intención de mejorar la calidad de vida o minimizar determinadas dolencias. Sin embargo, la penetración de este tipo de prácticas puede contribuir a conformar un escenario del bienestar social, que se concreta en problemas de salud pública (López-Cantos, 2017) y en una manipulación emocional para mitigar los miedos (Sagan, 2000; Shermer, 1997). Además, en la mayor parte de los casos, la difusión de estas terapias posee ánimo fraudulento $\mathrm{y} / \mathrm{o}$ integran propósito de lucro (Dawkins, 1998).

Diversos estudios confirman que el uso de las terapias alternativas y complementarias, es superior en mujeres (Cano-Orón et al., 2018; Broom, 2012; Al-Windi, 2004). Además, recientes investigaciones constatan la utilización de este tipo de terapias entre pacientes pediátricos (Adams, et al., 2013; Valicenti-McDermott, 2013). Ello se debe, especialmente, a la aplicación de estas prácticas por parte de mujeres interesadas en dichas pseudoterapias que tienen menores a su cargo con dolencias crónicas o incurables y buscan información para paliar el dolor o mejorar la calidad de vida de estos niños enfermos.

La globalización de la sociedad y de la medicina a través del uso de internet, en ocasiones como única fuente de consulta, ha llevado a que las CAM hayan podido captar la atención de diferentes públicos gracias a su difusión a través de redes sociales que escapan a cualquier control de rigurosidad en el contenido y mezclan de manera indistinta, falsas creencias, con tradiciones o filosofías en el área de la salud. La penetración de las CAM en el tejido social junto con la amplia difusión que las actuales herramientas comunicativas permiten, están otorgando a estas prácticas legitimidad (Alonso y Cortiñas, 2014a). El declive en el que, actualmente, se sumergen los discursos científicos y la información de calidad (Cortiñas y Alonso, 2014) conlleva que la aceptación de este tipo de prácticas sea todavía más palpable. El barómetro del CIS de febrero de 2018 incluye, por primera vez, diversas cuestiones en torno a las terapias alternativas, tales como la homeopatía y el reiki. Los resultados revelan un gran desconocimiento por parte de la sociedad española sobre la diferencia entre los tratamientos médicos y falsos remedios (CIS, 2018). Estas terapias constituyen así la explicación ilusoria para aquellas cuestiones en las que un individuo no encuentra una respuesta satisfactoria en la ciencia.

A través de los medios de comunicación la sociedad configura la imagen de la ciencia (Entwistle y Hancock-Beaulieu, 1992), estructurando su tejido social y generando opiniones (MacQuail, 2000; Lippmann, 2003). Este hecho conlleva que la difusión sobre el uso de terapias alternativas a través de los mass media otorgue al fenómeno un aura de 
cotidianeidad y de aprobación, fundamentalmente por la credibilidad que se les supone a los medios de comunicación (Armentia, 2002).

El incremento en el consumo de contenidos audiovisuales en red contribuye a la generalización de estas prácticas. Cada vez más, los ciudadanos emplean las plataformas interactivas para acceder a información, ya sea generalista o especializada, sobre todo entre los jóvenes (Tejedor-Calvo, et al., 2018:295).

Según la VIII Encuesta de Percepción Social de la Ciencia elaborada por FECYT (2017), las plataformas más utilizadas entre las personas que utilizan internet para buscar información son las redes sociales $(75,4 \%)$ y los contenidos audiovisuales $(62,3 \%)$. Millones de usuarios emplean esta plataforma diariamente como motor de búsqueda para consumir vídeos de cualquier temática. Según los datos aportados por la Consultora especializada Tubular Labs2, España es el segundo país europeo que más contenido exporta a la red en forma de vídeos. Además, el $72 \%$ del material publicado en la red y que es generado por usuarios españoles se consume en países extranjeros, siendo los principales mercados internacionales países como México (18\% del consumo) y Argentina (14\%).

Además, las plataformas de social media han elevado el grado de participación e interacción de los usuarios y han facilitado su acceso a contenidos específicos (Boyd, 2007). Este hecho ha potenciado la relación con otros internautas, conformando así sus identidades y ecosistemas digitales (Cheung et al., 2011 1). La red posibilita que los usuarios se conviertan en productores de información, lo que ha motivado que elaboren, intercambien y promocionen sus propios contenidos (Chung et al., 2016), convirtiéndose en cómplices mediáticos con respecto a la difusión de los mensajes que integran sus intereses concretos (Gentile et al., 2012). Asimismo, internet brinda la posibilidad de elaborar contenidos hipertextuales, multimedia e interactivos y transmedia (Tejedor-Calvo, et al., 2018:298).

Según el informe de Audiencia de Internet abril/mayo de 2018 elaborado para el Estudio General de Medios de la Asociación para la Investigación de Medios de Comunicación, YouTube es el sitio de internet más visitado por los internautas, seguido por Facebook, con 25.329.000 y 19.926 .000 usuarios únicos respectivamente, en abril-mayo (AIMC, 2018:11).

\section{Objeto de estudio}

El objetivo del presente estudio es analizar cómo se construye el imaginario social de las terapias naturales, complementarias y alternativas a través de su discurso en redes sociales. Para ello, se ha analizado el canal temático "Terapias alternativas y remedios naturales" de la plataforma YouTube, creado el 16 de noviembre de 2016.

Su elección se ha debido a dos factores: es el canal temático en español sobre terapias alternativas y complementarias que cuenta con un mayor número de suscriptores en el momento de iniciarse este estudio; en su denominación engloba los términos que son motivo de análisis en el proyecto de investigación al que se vincula este trabajo. La propia denominación del canal temático analizado, "Terapias alternativas y remedios naturales", es en sí significativa porque en su nomenclatura conviven tanto las terapias alternativas, es decir, las que se administran en lugar de los tratamientos convencionales y los remedios naturales, que formarían parte de esas terapias complementarias que pueden administrarse simultáneamente con tratamientos convencionales.

2 Tubular Labs es una consultora inglesa especializada en analizar el consumo de vídeos multiplataforma a nivel mundial para todos los dispositivos y realiza informes periódicos de consumo en las diferentes redes sociales. Estos datos se han extraído del informe de consumo de 2016, el último que aparece publicado. En https://tubularlabs.com/research-guides/state-online-video-2016-review-youtube-video-report. Consultado el 29/07/2018. 
En la actualidad, el canal "Terapias alternativas y remedios naturales" posee cerca de 40.000 suscriptores. En 2017, incluía 128 vídeos, 15.795 suscriptores y 1.353 .759 visualizaciones. No obstante, en julio de 2018 se constata la reducción del número de vídeos, dado que, a pesar de las nuevas producciones añadidas, desaparecen los contenidos que en el año anterior habían obtenido más visualizaciones3.

Tabla 1. Datos del canal de YouTube

\begin{tabular}{|l|l|l|l|}
\hline Año muestra & Suscriptores & Vídeos & Visualizaciones canal \\
\hline $\mathbf{2 0 1 7}$ & 15.7954 & 128 & 1.353 .579 \\
\hline $\mathbf{2 0 1 8}$ & 38.106 & 109 & 604.912 \\
\hline
\end{tabular}

Se examina qué ideas e imágenes transmite este canal al imaginario social en sus formas y estrategias de comunicación utilizadas y se analiza cómo estos contenidos se divulgan también a través de otras redes sociales y sitios web: concretamente, a través de una página de Facebook y una página web que poseen el mismo nombre que el canal de YouTube. De esta forma, se concreta la finalidad de estas sinergias entre las diferentes plataformas y se busca determinar si, además del objetivo de dar difusión a estas terapias, existe también una intencionalidad diferente, como podría ser la lucrativa.

\section{Metodología}

El corpus está compuesto por los vídeos del canal "Terapias alternativas y remedios naturales" de la plataforma YouTube. La muestra analizada, conformada por 40 vídeos por año, se ha recogido en dos periodos: el 30 de julio de 2017 y el 30 de julio de 2018 . Con este objetivo, en 2017 se examinaron los 20 vídeos más visionados y los 20 menos visionados. En 2018 , se repitió el mismo procedimiento y el resultado se materializa en dos grupos separados cronológicamente por un año. Así pues, en ambas recopilaciones, los vídeos fueron ordenados en función del número de reproducciones para seleccionar los más populares y los menos exitosos.

La razón de esta selección estriba en que se ha considerado relevante establecer una comparativa entre los contenidos más y menos visitados, comprobar su evolución a través del tiempo y determinar las preferencias de los usuarios del canal, así como la reorganización de contenidos y la orientación cada vez más comercial. Para realizar la recogida de datos sobre las características de los vídeos se ha cumplimentado una tabla diseñada a tal efecto, a partir de la ficha de vaciado de datos de Moreno-Castro (2016). Así pues, se clasifican las características de los vídeos desde el punto de vista de la producción, así como del resultado final para distinguir entre vídeos de calidad profesional o amateur.

Desde la perspectiva del enfoque, se realiza un análisis cualitativo del contenido para determinar si se utilizan mensajes con intención informativa o divulgativa o se trata de vídeos con intención comercial de venta de productos o servicios relacionados con estas terapias. También se examina si las piezas contienen material de ficción y entretenimiento.

De este modo, las variables analizadas son:

\footnotetext{
3 Se observa que de un año a otro se eliminan los vídeos que tenían más éxito y, por extensión, disminuye el número de reproducciones en el canal. Los vídeos eliminados son los que trataban la temática de los Códigos Sagrados. 4 El día de la selección y captura del material audiovisual en 2017 el canal contaba con 15.795 suscriptores y un total de 1.353 .579 visualizaciones. Información del 31 de julio de 2017 a las $20.00 \mathrm{~h}$. El día de la selección y captura del material audiovisual en 2018 el canal contaba con 38.106 suscriptores y un total de 604.912 visualizaciones. Información del 31 de julio de 2018 a las $22.00 \mathrm{~h}$.
} 
- $\quad$ título del vídeo y orden de posición en el canal según número de visualizaciones,

- duración de cada pieza;

- número de reproducciones;

- tipo de producción: profesional o amateur;

- tipo de montaje: narrativo (clásico), creativo o ideológico;

- posicionamiento con respecto a la práctica de la que trata el vídeo: a favor o en contra;

- procedencia del contenido: privado o institucional;

- modo de expresión predominante: descriptivo, narrativo, argumentativo y relato de experiencias propias.

En las dos muestras analizadas, separadas cronológicamente por un año, se recoge un conjunto total de 62 vídeos, dado que en 2018 se analizan 22 nuevas piezas y las restantes 18 se repiten con respecto al año anterior5.

El seguimiento de este canal nos permite examinar su evolución y la extensión de su contenido a otras redes sociales, concretamente a Facebook, mediante una FanPage con el mismo nombre, pero también a una página web que alberga una tienda online en la que se comercializan diversos de los productos utilizados en las prácticas difundidas a través de los vídeos en Youtube.

Del mismo modo, en el canal Youtube y en la FanPage, se han rastreado los comentarios asociados a los vídeos analizados para determinar el perfil de sus usuarios.

En la siguiente tabla se muestran el resumen del análisis cualitativo de las 62 piezas examinadas en 2017 y en 2018 . Su orden obedece al número de visualizaciones obtenidas en 2018.

2 Análisis cualitativo de las piezas de 2017 y 2018

\begin{tabular}{|l|l|l|l|l|l|l|}
\hline Tí́tulo del vídeo & Duración & $\begin{array}{l}\text { Visualizacion } \\
\text { es }\end{array}$ & $\begin{array}{l}\text { Producción } \\
\text {-Montaje }\end{array}$ & $\begin{array}{l}\text { Postura a } \\
\text { favor/en } \\
\text { contra }\end{array}$ & $\begin{array}{l}\text { Privado/ } \\
\text { Institucion } \\
\text { al }\end{array}$ & $\begin{array}{l}\text { Modo } \\
\text { expresión } \\
\text { predominan } \\
\text { te }\end{array}$ \\
\hline $\begin{array}{l}\text { 1. Limpieza de 9 días con los Códigos } \\
\text { Sagrados de Agesta }\end{array}$ & $42: 18$ & 447.858 & $\begin{array}{l}\text { Amateur- } \\
\text { Narrativo }\end{array}$ & A favor & Privado & Descriptivo \\
\hline $\begin{array}{l}\text { 2. Ejercicio de 18 días para flujo de } \\
\text { dinero con Códigos Sagrados de } \\
\text { Agesta }\end{array}$ & $33: 23$ & 186.394 & $\begin{array}{l}\text { Amateur- } \\
\text { Narrativo }\end{array}$ & A favor & Privado & Descriptivo \\
\hline $\begin{array}{l}\text { 3. Oración de Co-Creación Kryon. La } \\
\text { oración que cambia el Mundo. }\end{array}$ & $15: 19$ & 130.267 & $\begin{array}{l}\text { Amateur- } \\
\text { Narrativo }\end{array}$ & A favor & Privado & Descriptivo \\
\hline $\begin{array}{l}\text { 4. Ejercicio de protección de 21 días } \\
\text { con Códigos Sagrados de Agesta }\end{array}$ & $1: 16: 18$ & 84.693 & $\begin{array}{l}\text { Amateur- } \\
\text { Narrativo }\end{array}$ & A favor & Privado & Descriptivo \\
\hline $\begin{array}{l}\text { 5. Oración de Co-creación Kyron. La } \\
\text { oración de cambia el mundo }\end{array}$ & $15: 19$ & 81.036 & $\begin{array}{l}\text { Amateur- } \\
\text { Narrativo }\end{array}$ & A favor & Privado & Descriptivo \\
\hline
\end{tabular}

\footnotetext{
5 En 2017 se analizan 40 piezas, los 20 vídeos más vistos y los 20 vídeos menos vistos. En 2018 , se analizan 22 nuevas piezas: de los 20 vídeos más vistos se repiten 2 con respecto al año anterior, mientras que de los 20 vídeos menos vistos se repiten 16. Por tanto, los vídeos repetidos son 18 y entre ambas muestras se analizan un total de 62 piezas.
} 


\begin{tabular}{|c|c|c|c|c|c|c|}
\hline $\begin{array}{l}\text { 6. Cómo Escoger una Piedra. Cómo } \\
\text { Limpiar una Piedra. Cómo Programar } \\
\text { una piedra }\end{array}$ & $5: 26$ & 70.819 & $\begin{array}{l}\text { Amateur- } \\
\text { Narrativo }\end{array}$ & A favor & Privado & Descriptivo \\
\hline $\begin{array}{l}\text { 7. Código Sagrado para ganar la } \\
\text { Lotería. Código Sagrado para ser } \\
\text { afortunado en los juegos de azar }\end{array}$ & $2: 16$ & 58.622 & $\begin{array}{l}\text { Amateur- } \\
\text { Narrativo }\end{array}$ & A favor & Privado & Descriptivo \\
\hline $\begin{array}{l}\text { 8. Ejercicio para Bajar de Peso con } \\
\text { Códigos Sagrados de Agesta }\end{array}$ & $40: 33$ & 36.938 & $\begin{array}{l}\text { Amateur- } \\
\text { Narrativo }\end{array}$ & A favor & Privado & Descriptivo \\
\hline $\begin{array}{l}\text { 9. Código Sagrado para el amor } \\
\text { incondicional. Guerreros de la Luz }\end{array}$ & $5: 46$ & 36.109 & $\begin{array}{l}\text { Amateur- } \\
\text { Narrativo }\end{array}$ & A favor & Privado & Descriptivo \\
\hline $\begin{array}{l}\text { 10. Ejercicio para el Trabajo Deseado } \\
\text { con Códigos Sagrados de Agesta }\end{array}$ & $26: 06$ & 33.183 & $\begin{array}{l}\text { Amateur- } \\
\text { Narrativo }\end{array}$ & A favor & Privado & Descriptivo \\
\hline $\begin{array}{l}\text { 11. Código Sagrado de Agesta para } \\
\text { atraer velozmente el compañero o la } \\
\text { compañera de vida }\end{array}$ & $3: 57$ & 26.691 & $\begin{array}{l}\text { Amateur- } \\
\text { Narrativo }\end{array}$ & A favor & Privado & Descriptivo \\
\hline $\begin{array}{l}\text { 12. ¿Qué es el Péndulo? Como } \\
\text { funciona y como usarlo. Radiestesia. }\end{array}$ & $9: 57$ & 23.220 & $\begin{array}{l}\text { Amateur- } \\
\text { Narrativo }\end{array}$ & A favor & Privado & Descriptivo \\
\hline $\begin{array}{l}\text { 13. Test Eneagrama. Test Rápido de } \\
\text { Identificación del Eneagrama }\end{array}$ & $8: 54$ & 20.975 & $\begin{array}{l}\text { Amateur- } \\
\text { Narrativo }\end{array}$ & A favor & Privado & Descriptivo \\
\hline $\begin{array}{l}\text { 14. Ejercicio Ho'oponopono con } \\
\text { Códigos Sagrados de Agesta }\end{array}$ & $11: 55$ & 15.183 & $\begin{array}{l}\text { Amateur- } \\
\text { Narrativo }\end{array}$ & A favor & Privado & Descriptivo \\
\hline $\begin{array}{l}\text { 15. Qué es el Eneagrama de la } \\
\text { personalidad y los } 9 \text { Eneatipos }\end{array}$ & $9: 51$ & 15.087 & $\begin{array}{l}\text { Amateur- } \\
\text { Narrativo }\end{array}$ & A favor & Privado & Descriptivo \\
\hline $\begin{array}{l}\text { 16. Amatista. Propiedades y usos de } \\
\text { la Amatista. Gemoterapia }\end{array}$ & $3: 14$ & 12.277 & $\begin{array}{l}\text { Amateur- } \\
\text { Narrativo }\end{array}$ & A favor & Privado & Descriptivo \\
\hline $\begin{array}{l}\text { 17. Beneficios y Propiedades de la } \\
\text { Obsidiana }\end{array}$ & $7: 00$ & 11.522 & $\begin{array}{l}\text { Amateur- } \\
\text { Narrativo }\end{array}$ & A favor & Privado & Descriptivo \\
\hline $\begin{array}{l}\text { 18. Propiedades de la Ágata Azul- } \\
\text { Gemoterapia }\end{array}$ & $2: 19$ & 11.332 & $\begin{array}{l}\text { Amateur- } \\
\text { Narrativo }\end{array}$ & A favor & Privado & Descriptivo \\
\hline $\begin{array}{l}\text { 19. Decretos para Atraer dinero, } \\
\text { prosperidad y abundancia }\end{array}$ & $1: 51$ & 11.242 & $\begin{array}{l}\text { Amateur- } \\
\text { Narrativo }\end{array}$ & A favor & Privado & Descriptivo \\
\hline $\begin{array}{l}\text { 20. ¿Cómo atraer clientes? Código } \\
\text { Sagrado para Atraer Clientes }\end{array}$ & $3: 29$ & 10.232 & $\begin{array}{l}\text { Amateur- } \\
\text { Narrativo }\end{array}$ & A favor & Privado & Descriptivo \\
\hline $\begin{array}{l}\text { 21. Propiedades y Beneficios de la } \\
\text { Hematites }\end{array}$ & $6: 04$ & 9.880 & $\begin{array}{l}\text { Amateur- } \\
\text { Narrativo }\end{array}$ & A favor & Privado & Descriptivo \\
\hline 22. Agua Solar Azul. Ho'oponopono & $1: 25$ & 9.854 & $\begin{array}{l}\text { Amateur- } \\
\text { Narrativo }\end{array}$ & A favor & Privado & Descriptivo \\
\hline $\begin{array}{l}\text { 23. Cuarzo Citrino. Propiedades y } \\
\text { Usos del Citrino. Gemoterapia }\end{array}$ & $1: 58$ & 9.408 & $\begin{array}{l}\text { Amateur- } \\
\text { Narrativo }\end{array}$ & A favor & Privado & Descriptivo \\
\hline $\begin{array}{l}\text { 24. Ejercicio para desarrollar Dones } \\
\text { con Códigos Sagrados de Agesta }\end{array}$ & $52: 23$ & 9.061 & $\begin{array}{l}\text { Amateur- } \\
\text { Narrativo }\end{array}$ & A favor & Privado & Descriptivo \\
\hline $\begin{array}{l}\text { 25. Código Sagrado de Agesta para } \\
\text { obtener Fuentes de Ingresos } \\
\text { Adicionales }\end{array}$ & $2: 10$ & 8.913 & $\begin{array}{l}\text { Amateur- } \\
\text { Narrativo }\end{array}$ & A favor & Privado & Descriptivo \\
\hline $\begin{array}{l}\text { 26. Código Sagrado para la } \\
\text { Prosperidad y la Abundancia }\end{array}$ & $2: 43$ & 7.784 & $\begin{array}{l}\text { Amateur- } \\
\text { Narrativo }\end{array}$ & A favor & Privado & Descriptivo \\
\hline
\end{tabular}




\begin{tabular}{|c|c|c|c|c|c|c|}
\hline $\begin{array}{l}\text { 27. Propiedades del Agata de Fuego } \\
\text { - Gemoterapia }\end{array}$ & $2: 44$ & 7.767 & $\begin{array}{l}\text { Amateur- } \\
\text { Narrativo }\end{array}$ & A favor & Privado & Descriptivo \\
\hline $\begin{array}{l}\text { 28. Código Sagrado de Agesta para } \\
\text { fortalecer la Relación y el Amor de } \\
\text { Pareja }\end{array}$ & $2: 10$ & 7.734 & $\begin{array}{l}\text { Amateur- } \\
\text { Narrativo }\end{array}$ & A favor & Privado & Descriptivo \\
\hline $\begin{array}{l}\text { 29. Código Sagrado de Agesta para } \\
\text { atraer el Amor de mi Vida }\end{array}$ & $3: 26$ & 7.515 & $\begin{array}{l}\text { Amateur- } \\
\text { Narrativo }\end{array}$ & A favor & Privado & Descriptivo \\
\hline $\begin{array}{l}\text { 30. Los } 7 \text { Niveles de Consciencia } \\
\text { Humana. Espiritualidad. Niveles de } \\
\text { Consciencia }\end{array}$ & $17: 42$ & 7.147 & $\begin{array}{l}\text { Amateur- } \\
\text { Narrativo }\end{array}$ & A favor & Privado & Descriptivo \\
\hline $\begin{array}{l}\text { 31. Código Sagrado de Agesta para } \\
\text { tener los seres de luz a nuestro favor }\end{array}$ & $2: 35$ & 6.808 & $\begin{array}{l}\text { Amateur- } \\
\text { Narrativo }\end{array}$ & A favor & Privado & Descriptivo \\
\hline $\begin{array}{l}\text { 32. Código Sagrado de Agesta para } \\
\text { despejar los caminos }\end{array}$ & $2: 56$ & 6.434 & $\begin{array}{l}\text { Amateur- } \\
\text { Narrativo }\end{array}$ & A favor & Privado & Descriptivo \\
\hline $\begin{array}{lrr}33 . \quad \text { Oración } & \text { Agua Solar Azul. } \\
\text { Ho'oponopono. } & \text { Prosperidad } \\
\text { Abundancia } & & \\
\end{array}$ & $2: 03$ & 6.331 & $\begin{array}{l}\text { Amateur- } \\
\text { Narrativo }\end{array}$ & A favor & Privado & Descriptivo \\
\hline $\begin{array}{l}\text { 34. Como elevar tu vibración? Pide y } \\
\text { se te Dara- Esther y Abraham Hicks }\end{array}$ & $19: 28$ & 6.244 & $\begin{array}{l}\text { Amateur- } \\
\text { Narrativo }\end{array}$ & A favor & Privado & Descriptivo \\
\hline $\begin{array}{l}\text { 35. Colgante de Angel Espiritual De la } \\
\text { Energia Quantum Scalar }\end{array}$ & $5: 44$ & 6.209 & $\begin{array}{l}\text { Amateur- } \\
\text { Narrativo }\end{array}$ & A favor & Privado & Descriptivo \\
\hline $\begin{array}{l}\text { 36. Propiedades del Aceite Esencial } \\
\text { de Pachuli. Aromaterapia }\end{array}$ & $1: 11$ & 6.118 & $\begin{array}{l}\text { Amateur- } \\
\text { Narrativo }\end{array}$ & A favor & Privado & Descriptivo \\
\hline $\begin{array}{l}37 . \quad 432 \mathrm{~Hz} \text { Frequency. Música } \\
\text { Sanadora. Reiki Gong } 3 \text { minutos. } \\
\text { Música para Dormir. Sanar durmiendo }\end{array}$ & $1: 31: 37$ & 5.445 & $\begin{array}{l}\text { Amateur- } \\
\text { Narrativo }\end{array}$ & A favor & Privado & Descriptivo \\
\hline 38. Meditación al Arcángel Metatrón & $2: 07$ & 5.275 & $\begin{array}{l}\text { Amateur- } \\
\text { Narrativo }\end{array}$ & A favor & Privado & Descriptivo \\
\hline $\begin{array}{l}\text { 39. Séptimo Chackra Chackra Corona. } \\
\text { Sahasrara }\end{array}$ & $4: 44$ & 1064 & $\begin{array}{l}\text { Amateur- } \\
\text { Narrativo }\end{array}$ & A favor & Privado & Descriptivo \\
\hline $\begin{array}{l}\text { 40. Remedios naturales para combatir } \\
\text { la caspa }\end{array}$ & $2: 30$ & 876 & $\begin{array}{l}\text { Amateur- } \\
\text { Narrativo }\end{array}$ & A favor & Privado & Descriptivo \\
\hline $\begin{array}{l}\text { 41. Propiedades y beneficios de la } \\
\text { canela. Remedios con canela. } \\
\text { Contraindicaciones de la canela. }\end{array}$ & $8: 52$ & 642 & $\begin{array}{l}\text { Amateur- } \\
\text { Narrativo }\end{array}$ & A favor & Privado & Descriptivo \\
\hline $\begin{array}{l}\text { 42. Propiedades del jengibre. } \\
\text { Beneficios del } \\
\text { Contraindicaciones del Jengibre. }\end{array}$ & $4: 36$ & 601 & $\begin{array}{l}\text { Amateur- } \\
\text { Narrativo }\end{array}$ & A favor & Privado & Descriptivo \\
\hline $\begin{array}{l}\text { 43. Propiedades de aceite esencial de } \\
\text { romero. Aromaterapia }\end{array}$ & $2: 17$ & 477 & $\begin{array}{l}\text { Amateur- } \\
\text { Narrativo }\end{array}$ & A favor & Privado & Descriptivo \\
\hline $\begin{array}{l}\text { 44. Remedios naturales para el dolor } \\
\text { de muelas. Remedios para el dolor de } \\
\text { muelas }\end{array}$ & $5: 49$ & 442 & $\begin{array}{l}\text { Amateur- } \\
\text { Narrativo }\end{array}$ & A favor & Privado & Descriptivo \\
\hline $\begin{array}{l}\text { 45. Propiedades del aceite esencial } \\
\text { de Naranja. Aromaterapia }\end{array}$ & $0: 54$ & 398 & $\begin{array}{l}\text { Amateur- } \\
\text { Narrativo }\end{array}$ & A favor & Privado & Descriptivo \\
\hline 46. Qué es la Gemoterapia & $6: 17$ & 394 & $\begin{array}{l}\text { Amateur- } \\
\text { Narrativo }\end{array}$ & A favor & Privado & Descriptivo \\
\hline $\begin{array}{l}\text { 47. Piedras para atraer la } \\
\text { Prosperidad }\end{array}$ & $1: 12$ & 353 & $\begin{array}{l}\text { Amateur- } \\
\text { Narrativo }\end{array}$ & A favor & Privado & Descriptivo \\
\hline
\end{tabular}




\begin{tabular}{|c|c|c|c|c|c|c|}
\hline $\begin{array}{l}\text { 48. Propiedades del Aceite Esencial } \\
\text { de Azahar Aromaterapia }\end{array}$ & $1: 00$ & 359 & $\begin{array}{l}\text { Amateur- } \\
\text { Narrativo }\end{array}$ & A favor & Privado & Descriptivo \\
\hline $\begin{array}{l}\text { 49. Propiedades del Aceite Esencial } \\
\text { de Canela. Aromaterapia }\end{array}$ & $1: 06$ & 356 & $\begin{array}{l}\text { Amateur- } \\
\text { Narrativo }\end{array}$ & A favor & Privado & Descriptivo \\
\hline $\begin{array}{l}\text { 50. Propiedades del Aceite Esencial } \\
\text { de Eucalipto. Aromaterapia }\end{array}$ & $1: 04$ & 314 & $\begin{array}{l}\text { Amateur- } \\
\text { Narrativo }\end{array}$ & A favor & Privado & Descriptivo \\
\hline $\begin{array}{l}\text { 51. Depurar el intestino con plantas } \\
\text { medicinales remedios caseros }\end{array}$ & $4: 20$ & 276 & $\begin{array}{l}\text { Amateur- } \\
\text { Narrativo }\end{array}$ & A favor & Privado & Descriptivo \\
\hline 52. Cómo usar la piel de plátano & $1: 37$ & 242 & $\begin{array}{l}\text { Amateur- } \\
\text { Narrativo }\end{array}$ & A favor & Privado & Descriptivo \\
\hline 53. Qué es el reiki & $5: 30$ & 241 & $\begin{array}{l}\text { Amateur- } \\
\text { Narrativo }\end{array}$ & A favor & Privado & Descriptivo \\
\hline $\begin{array}{l}\text { 54. Aceite esencial de jazmín. } \\
\text { Propiedades del aceite esencial de } \\
\text { jazmín. Aromaterapia }\end{array}$ & $0: 47$ & 228 & $\begin{array}{l}\text { Amateur- } \\
\text { Narrativo }\end{array}$ & A favor & Privado & Descriptivo \\
\hline 55. Qué es la aromaterapia & $3: 39$ & 227 & $\begin{array}{l}\text { Amateur- } \\
\text { Narrativo }\end{array}$ & A favor & Privado & Descriptivo \\
\hline $\begin{array}{l}\text { 56. Piedras y gemas aconsejadas } \\
\text { para tratar el dolor. Gemoterapia }\end{array}$ & $1: 03$ & 199 & $\begin{array}{l}\text { Amateur- } \\
\text { Narrativo }\end{array}$ & A favor & Privado & Descriptivo \\
\hline $\begin{array}{l}\text { 57. Los } 5 \text { principios del Reiki solo por } \\
\text { hoy }\end{array}$ & $1: 40$ & 193 & $\begin{array}{l}\text { Amateur- } \\
\text { Narrativo }\end{array}$ & A favor & Privado & Descriptivo \\
\hline $\begin{array}{l}\text { 58. Propiedades del Aceite Esencial } \\
\text { de Lavanda. Aromaterapia }\end{array}$ & $0: 49$ & 194 & $\begin{array}{l}\text { Amateur- } \\
\text { Narrativo }\end{array}$ & A favor & Privado & Descriptivo \\
\hline $\begin{array}{l}\text { 59. Propiedades del Aceite Esencial } \\
\text { de Limón. Aromaterapia }\end{array}$ & $1: 05$ & 198 & $\begin{array}{l}\text { Amateur- } \\
\text { Narrativo }\end{array}$ & A favor & Privado & Descriptivo \\
\hline $\begin{array}{l}\text { 60. Aceite } \\
\text { Esencial de Menta } \\
\text { Propiedades Curativas del aceite } \\
\text { esencial de Menta. Aromaterapia } \\
\text { Menta }\end{array}$ & $1: 11$ & 179 & $\begin{array}{l}\text { Amateur- } \\
\text { Narrativo }\end{array}$ & A favor & Privado & Descriptivo \\
\hline $\begin{array}{l}\text { 61. Piedras para la aceptación } \\
\text { Gemoterapia }\end{array}$ & $1: 59$ & 170 & $\begin{array}{l}\text { Amateur- } \\
\text { Narrativo }\end{array}$ & A favor & Privado & Descriptivo \\
\hline 62. Remedios para el dolor menstrual & 6:07 & 86 & $\begin{array}{l}\text { Amateur- } \\
\text { Narrativo }\end{array}$ & A favor & Privado & Descriptivo \\
\hline
\end{tabular}

\section{Resultados}

El análisis de contenido de los vídeos, así como la comparación entre aquellos que presentan mayor y menor número de visualizaciones, ha permitido extraer unos resultados que posibilitan medir la utilidad del canal, así como la preferencia de contenidos que tienen los internautas. latinoamericanos, siendo las mujeres el sexo mayoritario entre los usuarios de este canal.

Del mismo modo, se ha examinado su relación con otras redes sociales, a fin de determinar los motivos que impulsan la elaboración y difusión de este tipo de contenidos.

De igual manera, se ha podido constatar el interés por estos temas tanto en España como en otros países latinoamericanos, siendo las mujeres el sexo mayoritario entre los usuarios de este canal.

\section{Gráfico 1. Preferencias de los usuarios en 2017}




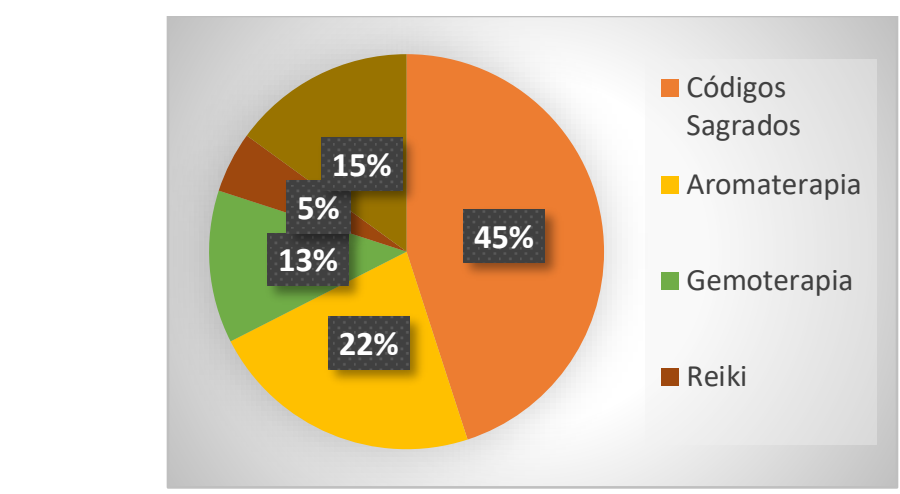

Fuente: Elaboración propia.

De las 20 piezas que en 2017 contaban con mayor número de visualizaciones, 18 abordaban los Códigos Sagrados de Agestab, una práctica no contemplada en el informe del Ministerio de Sanidad (2011) sobre el estudio de la situación de las terapias alternativas. Un año después, al analizar los vídeos con más reproducciones se observa que el número de vídeos disponibles disminuye de forma considerable. Este hecho es debido a que los 18 vídeos que abordaban los Códigos Sagrados de Agesta fueron retirados del canal, a pesar de que se trataba de una de las temáticas más demandadas por los suscriptores. La temática de los vídeos con menor número de visualizaciones combina los remedios naturales con terapias alternativas como el reiki, aromaterapia, fitoterapia y gemoterapia.

En 2018 se observa la inclusión de 18 nuevas piezas. Ante la desaparición de las piezas sobre Códigos Sagrados, las temáticas más relevantes entre los vídeos más vistos en 2018 destacan los relativos a eneagramas de personalidad y a prácticas como meditación, gemoterapia y, en menor medida, aromaterapia y reiki. Por tanto, la temática de los vídeos más vistos en 2018 , coinciden en gran medida con las tratadas en los vídeos menos populares.

\title{
Gráfico 2. Preferencias de los usuarios en 2018
}

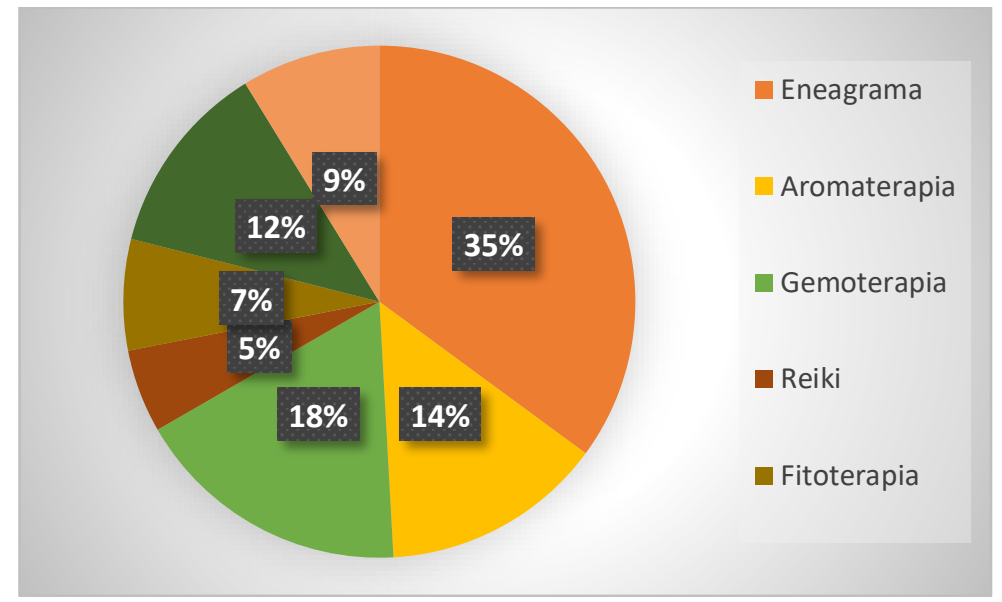

\begin{abstract}
6 Los Códigos Sagrados Numéricos son descritos como recursos para lograr aquello que se desee. Basados en una matemática misteriosa de otras dimensiones, estos códigos están canalizados a través de José Gabriel Agesta, que asegura poseer conexión directa con los seres de luz y periódicamente actualiza las cifras secretas. Consiste en repetir hasta 45 veces una determinada cifra para activar el correspondiente código y, según los practicantes de esta disciplina, alcanzar el objetivo para el cual se invoca, ya sea encontrar empleo, amor, bajar de peso o curar una enfermedad. Cabe destacar que el vídeo Ejercicio para Bajar de Peso con Códigos Sagrados de Agesta incluye las cifras secretas para regular el metabolismo, mejorar el sistema digestivo y circulatorio y oxigenar las células.
\end{abstract}


Fuente: Elaboración propia.

Desde el punto de vista de la producción y la calidad audiovisual de los vídeos, en todos los casos se observan contenidos de carácter amateur, llevados a cabo con escasos recursos y conocimientos técnicos. Todos los vídeos analizados utilizan una misma cabecera (actualizada y animada a partir de 2018) que unifica el contenido del canal y les dota de cierta coherencia interna. Los planos siguientes consisten en imágenes fijas relacionadas con el tema que se está tratando y de duración muy extensa, muchas de ellas de baja calidad; sobre estas imágenes se inserta una locución para aportar la información correspondiente; la postproducción está poco cuidada, sin importar que las imágenes aparezcan pixeladas, con marcas de agua o frames en negro. Su realización es monótona, la resolución de las imágenes es insuficiente, la locución no es profesional y, en ocasiones, está grabada a través de un software que reproduce de manera mecánica un texto escrito, generando así una voz robótica y poco natural. Se emplea el texto sobreimpreso para destacar informaciones.

Predomina el enfoque informativo-divulgativo e incluso se intenta dar al contenido de la locución un estilo científico que se complementa con consejos y prescripciones para mejorar determinadas patologías como diabetes, diarrea, gastroenteritis, halitosis, etc. Además, se constata que este canal contribuye a la difusión de remedios no científicos con los riesgos que conlleva para la sociedad, tal y como alertan diversos autores (López-Cantos, 2017; Mulet, 2015), ya que en muchos casos puede generar confusión sobre la validez de estas terapias y afectar a la salud de las personas. Al enfoque informativo-divulgativo del tema que abordan los vídeos, se suma al final del mismo la intención comercial-publicitaria, que se concreta en una locución y un texto sobreimpresionado que insta a los usuarios a suscribirse al canal.

Por otra parte, tomando como premisa la investigación de Peñafiel-Saiz et al. (2014), se constata que el valor de la información está relacionado con la cantidad, calidad y pluralismo de las fuentes empleadas, especialmente en los contenidos referentes a temas de salud, donde es imprescindible que las fuentes sean citadas. Sin embargo, los mensajes difundidos en los vídeos analizados no contienen alusión directa a ningún tipo de fuente, por lo que no se tiene conocimiento de las posibles fuentes utilizadas, ni se contrasta la información que se muestra. Esta circunstancia determina la calidad de la información difundida, a la que se suma, como ya se ha dicho, una producción de carácter amateur.

Desde febrero de 2018, en el apartado Comunidad de la plataforma YouTube se incorpora una encuesta dirigida a conocer los contenidos que más interesan a los usuarios. Este cuestionario formado únicamente por dos preguntas con opciones de respuesta cerrada, pretende generar feedback con los usuarios del canal. Las preguntas giran en torno a qué temas les gustaría que se abordaran en los vídeos en directo y los temas que más les interesan (con 5 opciones de respuesta posibles que incluye la opción de Códigos Sagrados). De hecho, numerosos usuarios aprovechan dicho cuestionario para solicitar la inclusión de estos vídeos que, a partir del 30 de julio, comienzan a estar disponibles.

Por otra parte, sobre la imagen de la cabecera del canal se insertan dos enlaces: uno redirigido a la red social Facebook donde se aloja la FanPage "Terapias alternativas y remedios naturales"; otro vinculado a la empresa PayPal para gestionar las posibles donaciones económicas. Asimismo, destaca el propósito lucrativo de algunos vídeos, que hacen referencia a concursos en la FanPage y a la tienda online de la página web. 
Tabla 2. Características de los vídeos analizados en el canal "Terapias alternativas y remedios naturales" de Youtube en 2017 y 2018

\begin{tabular}{|c|c|c|}
\hline \multicolumn{3}{|c|}{20 VÍDEOS MÁS VISIONADOS } \\
\hline CONTENIDO & CARACTERÍSTICAS & $\begin{array}{ll}\text { Vídeos } & \text { que } \\
\text { cumplen las } \\
\text { características }\end{array}$ \\
\hline $\begin{array}{l}\text { CÓDIGOS SAGRADOS } \\
\text { ENEAGRAMA } \\
\text { GEMOTERAPIA } \\
\text { AROMATERAPIA } \\
\text { REIKI }\end{array}$ & $\begin{array}{ll}\text { - } & \text { Duración dispar. } \\
\text { - } & \text { Todos ellos superan las } 5.000 \text { visualizaciones. } \\
\text { - } & \text { Vídeos recientes. } \\
\text { - } \quad \text { Creados por la misma autora. } \\
\text { - } \quad \text { Baja calidad de la postproducción y material amateur }\end{array}$ & $90 \%$ \\
\hline \multicolumn{3}{|c|}{20 VÍDEOS MENOS VISIONADOS } \\
\hline CONTENIDO & CARACTERÍSTICAS & $\begin{array}{l}\text { Vídeos que } \\
\text { cumplen las } \\
\text { características }\end{array}$ \\
\hline $\begin{array}{l}\text { REIKI } \\
\text { GEMOTERAPIA } \\
\text { AROMATERAPIA } \\
\text { FITOTERAPIA }\end{array}$ & $\begin{array}{l}\text { - } \quad \text { Brevedad. } \\
\text { - } \quad \text { canguno de ellos supera las } 450 \text { visualizaciones durante el primer año de vida del } \\
\text { supera los } 1.000 \text { visionados (90). } \\
\text { - } \quad \text { Vídeos muy antiguos creados en los primeros meses de vida del canal. } \\
\text { - } \quad \text { Creados por la misma autora. } \\
\text { - Baja calidad de la postproducción y material amateur y poco cuidado. }\end{array}$ & $80 \%$ \\
\hline
\end{tabular}

Fuente: Elaboración propia.

El 29 de noviembre de 2016, dos semanas después de la creación del canal de Youtube, se publica la página de Facebook "Terapias alternativas y remedios naturales. Sus contenidos se posicionan claramente a favor de las terapias alternativas. Se ha accedido a los perfiles personales de los miembros del grupo. A través del seguimiento realizado, se han detectado los usuarios más activos para examinar cómo interactúan y conocer qué publicaciones son las que obtienen un mayor índice de interacción y participación. Precisamente es en esta red donde se muestra la finalidad comercial de los contenidos publicados, ya que enlazan directamente con la multinacional norteamericana de cosmética Nu Skin, donde la administradora es distribuidora en España.

Se constata que las publicaciones que más éxito tienen y que, además cuentan con una serie de seguidoras fieles, son las que recomiendan los productos de Nu Skin. Se produce así una retroalimentación a través de las comentaristas habituales de ambos canales que son a la vez, prescriptoras, consumidoras y, en realidad, distribuidoras de dichos productos, por lo que sus opiniones están condicionadas, sesgadas y orientadas a generar ventas.

Además de los canales en Youtube y Facebook, la administradora de estas redes sociales también gestiona la página web terapiasalternativasyremediosnaturales.com integrada por una tienda online y un blog. En el e-commerce se ofertan parte de los productos que se prescriben en los vídeos de Youtube: aceites, gemas, libros espirituales y demás mercancías relacionados directa $o$ indirectamente con el tema del canal. En el blog se publican contenidos complementarios a los divulgados en Youtube, aunque no con tanta regularidad. Además, al igual que en el canal de Youtube, la página web incluye la opción de realizar un donativo mediante PayPal. También ocupa un lugar destacado el enlace a la página de Facebook. No obstante, en julio de 2018 se observa una menor oferta de productos con respecto a 2017. Ello se debe a que la mayor parte del e-commerce de "Terapias alternativas y remedios 
naturales" se ha trasladado a la FanPage, donde se aprecia un evidente talante comercial, puesto que también se emplea como plataforma de venta de diferentes marcas y productos.

A partir de los comentarios asociados a los vídeos del canal de Youtube se constata que el $90 \%$ de los usuarios son mujeres y constituyen el público más activo. Las interacciones de los usuarios en la FanPage sugieren resultados similares.

La principal motivación de la responsable de estas redes sociales es comercial, dado que el objetivo del canal de Youtube es generar marketing de contenidos orientado a incrementar tráfico web hacia el e-commerce asociado (terapiasalternativasyremediosnaturales.com) y, especialmente, a la página de Facebook e incrementar las ventas de los productos que se ofertan.

En este sentido, la novedad en 2018 , desde el punto de vista del rendimiento económico, es la monetización de este canal en YouTube. Se trata de una opción que brinda la plataforma a los administradores y creadores de sus canales y les permite insertar publicidad de diferentes marcas antes de la reproducción de sus contenidos y obtener beneficios.

De esta manera, se distingue una quíntuple vía de ingresos: a través de la venta de productos de la tienda online (lámparas de sal, colgantes, amuletos, gemas, péndulos, etc.); mediante la venta de productos de cosmética y salud de Nu Skin (de los que logra un porcentaje sobre la venta); a través de los nuevos prescriptores para la multinacional (por lo que, presumiblemente, también recibe una bonificación y asciende en la estructura de marketing piramidal); por las donaciones puntuales al canal Youtube de suscriptores o internautas; finalmente por el pago por la publicidad insertada en el canal.

Por otra parte, en las redes analizadas, no se prescriben directamente tratamientos complementarios, aunque sí que se proponen remedios naturales como forma de minimizar o mejorar los síntomas de determinadas patologías. De hecho, existen usuarios que aprovechan el canal Youtube para solicitar vídeos en los que se ofrezcan "remedios" sobre enfermedades concretas como la diabetes o dolencias tan graves como un ataque cardiaco. Así, en los primeros vídeos publicados se aprecia que la autora y responsable del canal todavía no ha definido totalmente el estilo y los intereses entre sus suscriptores. No obstante, tras casi dos años de vigencia ha podido calibrar y reorientar los contenidos del canal en función de las preferencias de los usuarios.

Por tanto, con la finalidad de satisfacer las demandas de sus suscriptores y alcanzar los objetivos comerciales, la administradora de estas redes sociales transmite unas ideas al imaginario social favorable con respecto a la validez de las terapias alternativas y complementarias como una solución para lograr salud y bienestar.

\section{Discusión y conclusiones}

Los resultados obtenidos en el análisis del canal de Youtube muestran que, de los 20 vídeos más visionados en 2017, únicamente 2 también aparecen entre los más vistos de 2018. Los restantes 18, son piezas nuevas, ya que inicialmente correspondían a vídeos de Códigos Sagrados que desaparecieron del canal y fueron sustituidos por otros contenidos. En cambio, los vídeos menos populares se muestran estancos y bastante estables de un año a otro. Las temáticas de las piezas con mayor número de reproducciones en 2018 son las relativas al eneagrama de personalidad y a prácticas como gemoterapia y aromaterapia. Por tanto, a excepción de los Códigos Sagrados, los aspectos tratados en los vídeos más vistos en 2018, coinciden en gran medida con los abordados en los vídeos menos populares. La difusión de contenidos relacionados con las terapias alternativas y complementarias escapa a cualquier control, ya que España carece de normativas con respecto al uso de estas prácticas. Este hecho posibilita la producción de contenidos que, sin rigor científico, pueden contribuir a difundir prácticas que conllevan riesgos para la salud pública (López-Cantos, 2017). 
Internet ha permitido el acceso a contenidos específicos y las redes sociales han facilitado la producción de contenidos por parte de los usuarios y la interacción de los mismos, que han difundido mensajes en los que incorporan sus intereses, creando así su propio ecosistema digital. Este hecho se aprecia de forma concreta en los comentarios asociados a los vídeos del canal de Youtube analizado, donde los usuarios comparten sus inquietudes y amplifican sus mensajes, generando una comunidad digital específica. Un proceso similar tiene lugar en las publicaciones más populares de la FanPage analizada. Se evidencian así las teorías propuestas por Chung et al. (2016), Cheung et al. (2011) y (Gentile et al., 2012). Además, se aprecia que la mayor parte de los usuarios en las redes sociales analizadas son mujeres, en la línea de los resultados de otros estudios (Cano Orón et al., 2018; Al-Windi, 2004; Broom, 2012 ) en los que se concluye que los usuarios de las terapias alternativas y complementarias son mayoritariamente mujeres.

Por otra parte, se observa una intención comercial en el canal de Youtube: la misión de esta plataforma radica en producir material audiovisual para redirigir tráfico a la FanPage y web asociadas y generar ventas de los productos que ahí se ofertan. Asimismo, se confirma de manera cada vez más profesionalizada, las sinergias entre ambas redes sociales como plataformas para generar marketing de contenidos orientados a captar clientes potenciales y estructurar un modelo de negocio que proporcione ingresos. El hecho de activar la monetización del canal Youtube mediante la inclusión de publicidad de marcas ajenas que aparecen antes de la reproducción de los contenidos solicitados muestra la intención de lucrarse con esta actividad. Así pues, se comprueba la finalidad lucrativa y comercial que lleva aparejada la producción de este tipo de contenidos tal y como señala Dawkins (1998).

Las futuras líneas de investigación pasan por analizar las motivaciones y los atributos de los usuarios que tienen preferencia por exponerse a este tipo de mensajes, enfocando el tema abordado desde la perspectiva del receptor del contenido.

\section{Agradecimientos}

Las autoras desean agradecer las sugerencias realizadas por la profesora Carolina Moreno Castro, catedrática de Periodismo de la Universidad de Valencia, gracias a las cuales ha sido posible mejorar la calidad del presente trabajo. 


\section{Referencias bibliográficas}

A ADAMS D., DAGENAIS S., CLIFFORD T., BAYDALA L., KING W., HERVAS-MALO M., ef al. (2013). Complementary and alternative medicine use by pediatric specialty outpatients. Pediatrics, $131(2)$, pp. 225-32.

ALONSO, F. \& CORTIÑAS, S. (2014a). La pseudociencia y el poder de los medios de comunicación. La problemática ausencia de bases teóricas para afrontar el fenómeno. Historia y Comunicación Social, 9, pp.93-103.

ALONSO, F. \& CORTIÑAS, S. (2014b). La pseudociencia como (des)información tóxica. Una taxonomía para comprender el fenómeno y sus manifestaciones. Ámbitos. Revista Internacional de Comunicación, 24, pp. 1-14. Recuperado de: http:/ / www.redalyc.org/articulo.oa?id $=16832255007$

ALONSO, M.J., ALBARRACÍN G., CAMINAL, J. \& RODRÍGUEZ, N. (2008). Práctica y productos terapéuticos en medicinas complementarias y alternativas, ėmercado regulado o mercado libre? Atención Primaria, 40, pp. 571-575. http://dx.doi.org/10.1157/13128572.

AL-WINDI A. (2004). Determinants of complementary alternative medicine (CAM) use. Complement Ther Med, 12(2-3), pp. 99-111.

ARMENTIA, J. (2002). Ciencia vs pseudociencias. Mediatika. Cuadernos de Medios de Comunicación, 8, pp. 559-571. Recuperado de: http://ojs.euskoikaskuntza.eus/index.php/mediatika/article/view/127/147

ASOCIACIÓN PARA LA INVESTIGACIÓN DE MEDIOS DE COMUNICACIÓN (2018). Audiencia de Internet abril/mayo. EGM. Madrid: AIMC. Recuperado de: https://www.aimc.es/almccOnt3nt/uploads/2018/06/internet218.pdf

BOYD, D. (2007). "Why youth (heart) social network sites: the role of networked publics in teenage social life". En: D. Buckingham (ed.) The John D. and Catherine T. MacArthur Foundation Series on Digital Media and Learning. Cambridge - EEUU: MIT Press.

ROOM, A., KIRBY, E., SIBBRITT, D., ADAMS J. \& REFSHAUGE K. (2012). Use of complementary and alternative medicine by mid-age women with back pain: a national cross-sectional survey. BMC Complement Altern Med.

CANO-ORÓN, L. MENDOZA-POUDEREUX, I. \& MORENO-CASTRO, CAROLINA (2018). Perfil sociodemográfico del usuario de la homeopatía en España. Atención Primaria, pp. 1-7. https://doi.org/10.1016/i.aprim.2018.07.006

CENTRO DE INVESTIGACIONES SOCIOLÓGICAS - CIS (2018). Barómetro de febrero. Estudio 3205. Recuperado de: http://www.cis.es/cis/export/sites/default/Archivos/Marginales/3200_3219/ 3205/es3205mar.pdf

CHEUNG, C.M.K., CHIUA, P. Y. \& LEEB, M K.O. (2011). Online social networks: Why do students use Facebook? Computers in Human Behavior, 27(4), pp. 1337-1343.

CHUNG T., ANAZA, N. A., PARK, J. \& PHILLIPS A. H. (2016). Who's behind the screen? Segmenting social venture consumers through social media usage. Journal of Retailing and Consumer Services, 28, pp. 288-295. 
CORNEJO-VALLE, M. \& BLÁZQUEZ-RODRÍGUEZ, M. (2013). La convergencia de salud y espiritualidad en la sociedad postsecular. Las terapias alternativas y la constitución del ambiente holístico. Revista de antropología experimental, 13, pp. 11-30.

CORTIÑAS-ROVIRA, S. \& ALONSO-MARCOS, F. (2014). La decadencia de la sección de ciencia en los medios tradicionales. Prisma Social, 12, pp. 402-435.

DAWKINS, R. (1998). Unweaving the Rainbow. Boston, MA: Houghton Mifflin.

ENTWISTLE, V. \& HANCOCK-BEAULIEU, M. (1992). Health and medical coverage in the UK national press. Public Understanding of Science, 1(4), pp. 367-382.

FUNDACIÓN ESPAÑOLA PARA LA CIENCIA Y LA TECNOLOGÍA - FECYT (2017). VIII Encuesta de percepción social de la ciencia y la tecnología - Informe de Resultados. Recuperado de: https://www.fecyt.es/sites/default/files/news/attachments/2017/04/epscyt2016_informe final_web_fecyt.pdf

GENTILE B., TWENGE J.M., FREEMAN E.C. \& CAMPBELL, W.K. (2012). The effect of social networking websites on positive self-views: An experimental investigation. Computers in Human Behavior, 28(5), pp. 1929-1933.

INTERACTIVE ADVERTISING BUREAU SPAIN - IAB SPAIN (2018). Estudio anual de redes sociales. Recuperado de: https://iabspain.es/wp-content/uploads/estudio-redes-sociales2018_vreducida.pdf

LEAF, J. B., KASSARDJIAN, A., OPPENHEIM-LEAF, M. L., CIHON, J. H., TAUBMAN, M., LEAF, R. \& MCEACHIN, J. (2016). Social Thinking $®$ : Science, Pseudoscience, or Antiscience? Behav Analysis Practice, 9, pp. 152-157.

LIPPMANN, W. (2003). Opinión pública. Madrid: Cuadernos de Langre.

LÓPEZ-CANTOS, F. (2017). El discurso de la felicidad de las terapias alternativas en Facebook. Razón y Palabra, 21(98), pp. 381-393. Recuperado de: http://www.revistarazonypalabra.org/index.php/ryp/article/download/953/pdf

MCQUAIL, D. (2000). Introducción a la teoría de la comunicación de masas. Barcelona: Paidós.

MINISTERIO DE SANIDAD. (2011). Análisis de la situación de las terapias naturales. Recuperado de: http://www.mspsi.gob.es/novedades/docs/analisisSituacionTNatu.pdf

MORENO-CASTRO, C. (coord.). (2016). Campañas Institucionales en Salud Pública: El caso de la vacuna contra el virus VPH. Madrid: Dextra Editorial.

MULET, J.M. (2015). Medicinas sin engaños. Todo lo que necesitas saber sobre los peligros de la medicina alternativa. Barcelona: Ed. Destino.

PEÑAFIEL-SAIZ, C., CAMACHO-MARKINA, I., AIESTARAN-YARZA, A., RONCO-LÓPEZ, M., ECHEGARAY-EIZAGUIRRE, L. (2014). La divulgación de la información de salud: un reto de confianza entre sectores implicados, Revista Latina de Comunicación Social, 69, pp. 135-151. Recuperado de: http://www.revistalatinacs.org/069/paper/1005_UPV/08c.html

TEJEDOR-CALVO S., PORTALÉS-OLIVA, M. \& PUEYO-VILLA, S. (2018). Web 2.0 y tratamiento informativo en las principales revistas españolas de divulgación científica y de la pseudociencia. Revista Latina de Comunicación Social, 73, pp. 293-316. Recuperado de: http://www.revistalatinacs.org/073paper/1256/15es.html 
SAGAN, C. (2000). El mundo y sus demonios. Barcelona: Planeta.

SHERMER, M. (1997). Why people believe in weird things. Pseudoscience, superstition, and other confusions of our time. New York: Freeman and Company.

VALICENTI-MCDERMOTT, M., BURROWS, B., BERNSTEIN, L., HOTTINGER, K., LAWSON, K., SEIJO R., et al. (2013). Use of complementary and alternative medicine in children with autism and other developmental disabilities: associations with ethnicity, child comorbid symptoms, and parental stress. Journal of child neurology, 29(3), 360-367.

URIOS, C., CAMINAL, J., RODRÍGUEZ, N. \& PUIGPELAT, F. (2006). Estrategias regulativas para las medicinas complementarias y alternativas: hacia un modelo de entendimiento de prácticas de salud. Atención Primaria. 38, pp. 574-576. . 